\title{
EVALUATING RETAIL BANKING SERVICE QUALITY AND CONVENIENCE WITH MCDA TECHNIQUES: A CASE STUDY AT THE BANK BRANCH LEVEL
}

\author{
Fernando A. F. Ferreira ${ }^{1}$, Sérgio P. Santos ${ }^{2}$, \\ Paulo M. M. Rodrigues ${ }^{3}$, Ronald W. Spahr ${ }^{4}$ \\ ${ }^{1}$ School of Management and Technology, Polytechnic Institute of Santarém, \\ Complexo Andaluz, Apartado 295, 2001-904 Santarém, Portugal \\ ${ }^{2}$ Faculty of Economics, University of Algarve, Campus de Gambelas, \\ 8005-139 Faro, Portugal \\ ${ }^{3}$ Economics and Research Department, Banco de Portugal, Av. Almirante Reis 71, \\ 1150-012 Lisboa, Portugal \\ ${ }^{4}$ Fogelman College of Business and Economics, University of Memphis, Memphis, \\ TN 38152-3120, USA \\ E-mails: ${ }^{1}$ fernando.ferreira@esg.ipsantarem.pt (corresponding author); \\ ${ }^{2}$ ssantos@ualg.pt; ${ }^{3}$ pmrodrigues@bportugal.pt; ${ }^{4}$ rspahr@memphis.edu \\ Received 03 December 2011; accepted 05 March 2012
}

\begin{abstract}
The intangibility of banking services makes the evaluation of service quality and customer convenience difficult to measure. This paper aims to construct an integrated evaluation system for retail banking service quality and convenience at the bank branch level by combining cognitive mapping with measuring attractiveness by a categorical based evaluation technique. We strive to introduce transparency in the decision making process and add to the performance literature in retail banking. Strengths, weaknesses and practical applications of our multiple criteria evaluation system are also discussed.
\end{abstract}

Keywords: bank branch, cognitive mapping, multiple criteria decision analysis, performance evaluation, retail banking, service quality and convenience.

Reference to this paper should be made as follows: Ferreira, F. A. F.; Santos, S. P.; Rodrigues, P. M. M.; Spahr, R. W. 2014. Evaluating retail banking service quality and convenience with MCDA techniques: a case study at the bank branch level, Journal of Business Economics and Management 15(1): 1-21.

JEL Classification: C44, G21, L25, M10.

\section{Introduction}

Retail banking service quality and convenience at the bank branch level is difficult to measure because of its intrinsic intangibility and difficulty in identifying appropriate measurement factors. Bankers obviously recognize the importance of intangible factors, but under conditions of increasing competition, instability and pressures placed on operating margins, the evaluation of customer perceived service quality is fundamental to improvement initiatives. It is generally agreed that intensification of competition resulting from the recent world-wide economic crisis places additional pressure on already 
chronically low operating margins. Recent pressures have had direct implications in the way banks manage their service quality and define their customer approach. Also, as defended by Serna (2005) and Ferreira et al. (2011a), few would contest that bank branches still maintain an important role in retail banking. Thus, it is generally agreed that retail banking success depends strongly on the competitiveness and improvement of branch service systems where bank branch evaluation may be the primary tool in determining how to improve service quality and convenience.

Because of the importance of bank branch service quality and convenience to retail banking, significant literature exists regarding bank branch in retail banking performance (e.g. Athanassopoulos 1997; Jackson III et al. 2003; Karatepea et al. 2005; Arbore, Busacca 2009; Lee et al. 2011; Oliveira, von Hippelb 2011 - these contributions are further discussed in section 1). Nevertheless, despite the strengths and widespread application of current methodologies, each has specific shortcomings where clarification is required on a number of issues. According to Ferreira et al. (2011a), there are technical issues related to the method by which evaluation criteria are selected, and the way trade-offs among those same criteria are made explicit. By integrating cognitive mapping with measuring attractiveness by a categorical based evaluation technique (MACBETH) (Bana e Costa, Vansnick 1994; Bana e Costa et al. 2005), we aim to support the development of an integrated evaluation system for bank branch service quality and convenience, and overcome some current methodological limitations. Following Ferreira et al. (2011b), our integrated evaluation system will also add to the literature on performance evaluation in retail banking.

The multiple criteria evaluation system framework applied in this paper extends the work of Ferreira et al. (2011a), which was a result of several working sessions with a panel of directors from the most representative banks in Portugal. Since both studies make use of the same methodological tools, it should be clarified that the difference between them relies on the fact that Ferreira et al. (2011a) present a broader framework for bank branch performance evaluation, while our study is particularly focused on bank branch service quality and convenience. We know of no prior work integrating the use of cognitive mapping and MACBETH to support the conception of evaluation systems for retail banking service quality and convenience at the bank branch level.

The remainder of the paper is structured as follows. The next section includes an overview of the literature on the evaluation of bank branch service quality and convenience. Section 2 describes and illustrates the evaluation system designed in our study. Section 3 concludes the paper by discussing advantages and disadvantages of our framework, and presenting lines for future research.

\section{Bank branch service quality and convenience evaluation}

A number of different approaches have been developed to deal explicitly with bank branch performance evaluation. Ferreira et al. (2011a) categorize these approaches in four major groups of methods: (1) traditional coefficients or ratios; (2) parametric or econometric models; (3) non-parametric techniques, and (4) integrated systems for performance evaluation. According to the authors, remarkable progress in bank branch 
evaluation has occurred over the last few decades; however, none of these methods is without limitations. Traditional coefficients (or ratios), for example, have been criticized for being operationally limited when dealing with multiple criteria and providing lagged information (Lau, Sholihin 2005; Wu et al. 2006). On the other hand, parametric (or econometric) models have been criticized for requiring a prior specification of a cost or production function and their limitation in explaining causal relations among criteria. Following this line, non-parametric techniques (or distribution-free tools as they are also categorized) have been recognized as a step forward by the performance measurement literature, namely in terms of bank branch performance evaluation (Dekker, Post 2001; Halkos, Salamouris 2004; Paradi, Schaffnit 2004; Camanho, Dyson 2005; Yang 2009). One of the most widely and successfully applied non-parametric techniques is data envelopment analysis (DEA), introduced by Charnes et al. (1978), which allows handling multiple input and multiple output variables without requiring the a prior definition of a production function. Still, standard DEA models have been criticized for associating all deviations from the frontier to inefficiency, ignoring possible stochastic noise in the data and, even knowing that some outputs are not easily measurable, they accept the possibility of fully characterizing the production function. As a result of the perceived dissatisfaction with some of the previous identified shortcomings, integrated systems for performance evaluation have been conceived and improved over the years (for a broader discussion on business performance evaluation methodologies, see, for instance, Acar, Zehir 2010; Pan et al. 2012). However, in the banking context, integrated performance evaluation systems such as the balanced scorecard (BSC) (Kaplan, Norton 1992) have been largely unexplored. Except for a few essays in the banking context (e.g. Suwignjo et al. 2000; Ferreira et al. 2011a), integrated systems for performance measurement, with special emphasis on the BSC, are generally criticized for, among other things, over simplicity and not explicitly specifying how compensations among evaluation criteria are made (Brignall 1992; Neely et al. 1995; Davis, Albright 2004). As a complement to this discussion, Table 1 presents a synopsis of the literature on bank branch service quality and convenience performance evaluation. As is evident, despite the progress achieved, most limitations discussed are still present.

Based on the information in Table 1 and previous discussion, two major lines of criticism have been pointed out with regard to the four categories of methods. First, the method by which performance measures are often selected may lead to the omission of relevant evaluation criteria (Lovell, Pastor 1997; Manandhar, Tang 2002; Jahanshahloo et al. 2004; Camanho, Dyson 2005). Second, according to Suwignjo et al. (2000), Mihelis et al. (2001) and Wu et al. (2006), among others, a lack of transparency exists in the way compensations among those criteria are obtained. We illustrate, in the following sections of the paper, how the integrated use of cognitive mapping and the MACBETH process may improve the selection of appropriate performance measures and/or the calculation of compensations among evaluation criteria. 
Table 1. Previous work on bank branch service quality and convenience performance evaluation

\begin{tabular}{|c|c|c|}
\hline Author/s and Date & Methodology & Main Contribution and Main Limitation \\
\hline $\begin{array}{l}\text { Athanassopoulos } \\
\text { (1997) }\end{array}$ & $\begin{array}{l}\text { - Data envelopment } \\
\text { analysis methods } \\
\text { enhanced by the value } \\
\text { judgements of individual } \\
\text { branch managers }\end{array}$ & $\begin{array}{l}\text { - Empirical results are discussed from a } \\
\text { sample of sixty eight commercial bank } \\
\text { branches in Greece; } \\
\text { - DEA major limitations have been } \\
\text { recognized }\end{array}$ \\
\hline $\begin{array}{l}\text { Jackson III et al. } \\
(2003)\end{array}$ & $\begin{array}{l}\text { - Game theoretic model to } \\
\text { investigate the influence } \\
\text { of differing market } \\
\text { structures or competitive } \\
\text { conditions on a bank's } \\
\text { decision to increase } \\
\text { the level of quality of } \\
\text { the retail or consumer } \\
\text { services offered }\end{array}$ & $\begin{array}{l}\text { - Optional level of a bank's service quality } \\
\text { depends critically on the competitive } \\
\text { structure of the market, the degree of } \\
\text { demand interaction between banks and } \\
\text { the ease of imitation of competitors' } \\
\text { service quality innovations; } \\
\text { - Limited to a game theory application }\end{array}$ \\
\hline $\begin{array}{l}\text { Karatepea et al. } \\
(2005)\end{array}$ & $\begin{array}{l}\text { - Multi-stage, multi-phase } \\
\text { and multi-sample } \\
\text { approach }\end{array}$ & $\begin{array}{l}\text { - Construction of a parsimonious } 20 \text {-item } \\
\text { four-dimensional service quality scale; } \\
\text { - Results can hardly be considered } \\
\text { conclusive and, according to the authors, } \\
\text { more studies are needed to further } \\
\text { validate the four-factor service quality } \\
\text { measure derived in the study }\end{array}$ \\
\hline $\begin{array}{l}\text { Arbore and } \\
\text { Busacca (2009) }\end{array}$ & $\begin{array}{l}\text { - Revised version of the } \\
\text { traditional analyses based } \\
\text { on derived measures of } \\
\text { attribute importance }\end{array}$ & $\begin{array}{l}\text { - The results of an extensive study on the } \\
\text { determinants of customer satisfaction in } \\
\text { Italy are presented; } \\
\text { - Exploratory nature of the research, whose } \\
\text { main goal was to illustrate a different } \\
\text { approach for an improved analysis of } \\
\text { satisfaction and dissatisfaction drivers }\end{array}$ \\
\hline Lee et al. (2011) & $\begin{array}{l}\text { - Hypothesis tests } \\
\text { and surveys }\end{array}$ & $\begin{array}{l}\text { - The study offers a unique integration } \\
\text { of three distinct domains of the } \\
\text { management literature (i.e. banking } \\
\text { operations, transformational leadership } \\
\text { and quality management); } \\
\text { - Relatively small sample size, and the } \\
\text { data of the study were collected through } \\
\text { cross-sectional surveys }\end{array}$ \\
\hline $\begin{array}{l}\text { Oliveira and von } \\
\text { Hippelb (2011) }\end{array}$ & $\begin{array}{l}\text { - Locus of innovation } \\
\text { determinations }\end{array}$ & $\begin{array}{l}\text { - First quantitative exploration of the } \\
\text { importance of services innovation } \\
\text { by users, focusing on the field of } \\
\text { commercial and retail banking services; } \\
\text { - Different types of sample limitation }\end{array}$ \\
\hline
\end{tabular}




\section{A "new" system for bank branch service quality and convenience evaluation}

It is generally recognized in the cognitive mapping literature that cognitive maps are important instruments for the structuring process of complex problems (Ackermann, Eden 2001; Eden, Ackermann 2001b; Belton, Stewart 2002; Eden, Banville 2003; Eden 2004; Ackermann, Eden 2011; Howick, Ackermann 2011; Ackermann 2012). Because cognitive maps are simple, interactive and extremely versatile, they promote discussion among the agents involved in a decision making process. This allows increased transparency and a reduction of omitted criteria. Thus, simplicity and transparency lead to a better understanding of the problem under consideration.

MACBETH, also an interactive approach, was created in the 1990s by Bana e Costa and Vansnick (Bana e Costa, Vansnick 1994; Bana e Costa et al. 2005). Technically, it is an interactive procedure conceived to quantify differences of attractiveness among elements of a certain set. Through a constructive learning process supported by visual interactive software (M-MACBETH), MACBETH is based on numerical scales of intervals. More specifically, the fulfilment of value judgement matrices allows for the definition of local preference scales for the different criteria involved in the decision process and assists the definition of cardinal value functions for the descriptors created (Bana e Costa et al. 2005). In our study, numerical interval scales are important to assist the calculation of trade-offs among criteria. As a particular technique in multiple criteria decision analysis (MCDA), MACBETH supports a constructivist based analysis, and uses a simple qualitative question-answer procedure that allows decision makers to enter the domain of cardinal measurement (Belton, Stewart 2002) (for other examples of MCDA techniques, see also Korsakiene 2004; Podvezko 2009). From this perspective, and given that MACBETH takes into account the professional experience of the decision makers involved in the process, it brings together humanistic, interactive and constructivist insights. Thus, the technique has great potential in dealing with weighted measurements in bank branch service quality and convenience evaluation, where most of the variables are intangible.

Following a constructivist approach, this study is organized in three phases. The structuring phase, which is concerned with the development of cognitive and strategic maps, allows us to identify important performance measures for bank branch service quality and convenience evaluation. The evaluation phase focuses on the application of MACBETH to allow for trade-offs among explicit criteria. Finally, the recommendations phase discusses the major advantages and shortcomings of the integrated use of these methods (i.e. cognitive maps and MACBETH) for bank branch service quality and convenience evaluation.

\subsection{The structuring phase}

During the structuring phase, a panel of decision makers and actors were organized, in several work sessions, to address the formulation of a "trigger question"; the conception of cognitive and strategic maps; and the definition of a tree of evaluation criteria, with associated descriptors and respective impact levels. 


\subsubsection{Actors involved}

The identification of a panel of relevant decision makers is a crucial procedure in the structuring process of complex problems, since decision makers are responsible for assisting the facilitator (i.e. scientist or researcher) during the conception of the performance framework.

In our study, the selection of the decision makers faced two major constraints: (1) limited availability of the decision makers and, consequently, (2) difficulties in getting the group together. Because of these constraints, contact was established with the Portuguese association of professional economists (i.e. Ordem dos Economistas before translation), which facilitated the selection of a panel composed of six top directors from the five largest banks in Portugal. The facilitator was also assisted by a psychologist and a communication technician, who helped in conducting the sessions and registering the results.

\subsubsection{Problem definition}

This study integrates cognitive maps and MACBETH to construct an evaluation framework for bank branch service quality and convenience. Thus, this integrated evaluation system will allow us to better assess bank branch performance in terms of service quality and convenience, and will provide improvement suggestions for each of the branches under evaluation.

\subsubsection{Individual cognitive maps}

Considering the limited availability of the experts involved, we decided to begin the structuring process following a technical procedure known as SODA I (illustrated in Fig. 1) - a variant of the strategic options development and analysis (SODA) approach (Eden, Ackermann 2001a, 2001b).

Following Figure 1, each individual session with decision makers began with detailed explanations concerning the role of cognitive maps to avoid confusion among decision makers and the facilitator's team. After these explanations, the operational phase began with the following "trigger question": "Based on your own values and professional experience, what are the main characteristics of a good bank branch in terms of quality of service and convenience?". The "post-its technique" was applied on a table $(130 \times 80 \mathrm{~cm})$ especially designed for our study. As reported in the literature (Ackermann, Eden 2001), the "post-its technique" consists of writing evaluation criteria on stickers - one post-it per criterion - and repeat the process until no more criteria are to be considered. The post-its are then organized by clusters (i.e. each cluster representing an area of concern), followed by additional discussion on their significance.

\subsubsection{Analyzing the linkages between criteria}

The next step after discussing the significance of each evaluation criteria is the internal analysis of each cluster's homogeneity (represented by post-its). The internal analysis is interactive and aims to identify and better understand the relationships among criteria. 


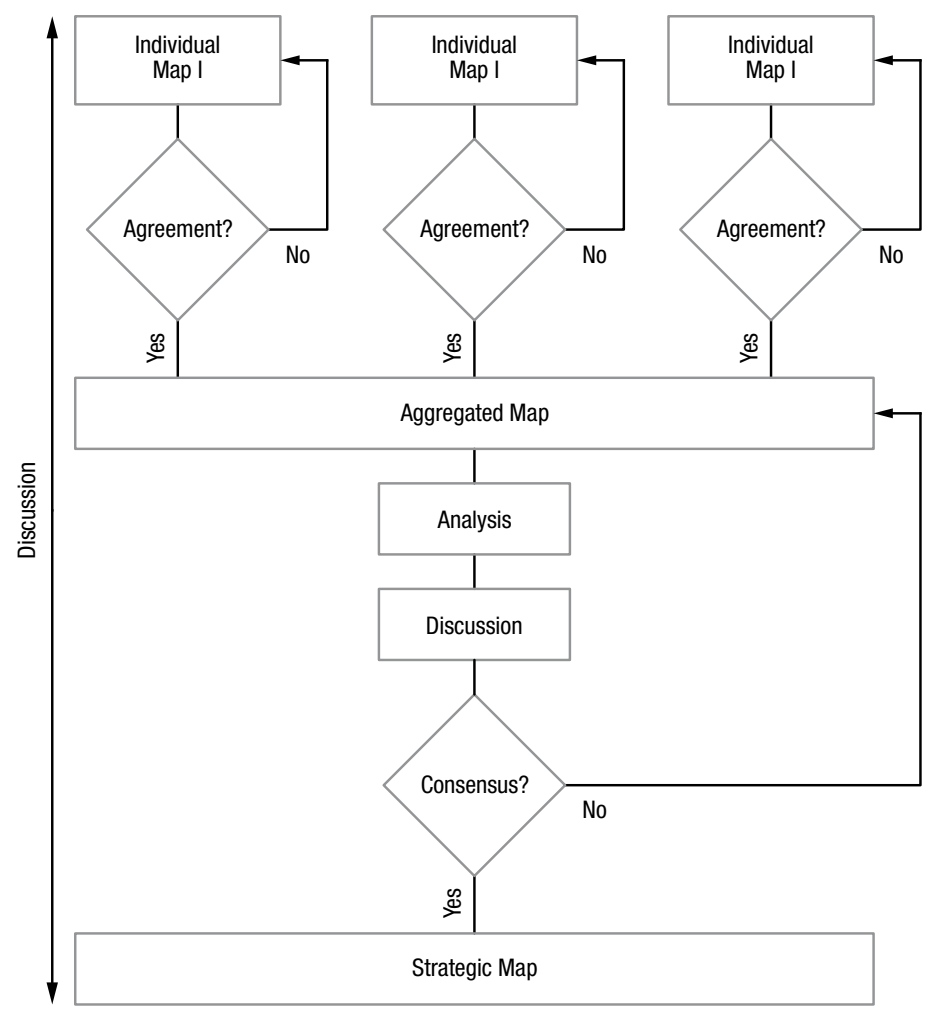

Fig. 1. SODA I conceptual scheme

The final step in this procedure is for decision makers and the communication technician to register all links (represented by arrows) in the individual cognitive map. As defended by Ackermann and Eden (2001), this last procedure should be accompanied by the opportunity to reflect, reshape and/or even restart the entire process.

\subsection{5. "Aggregated" and "strategic" maps}

Following the SODA I methodological guidelines, the task of aggregating the individual cognitive maps resulting from the individual sessions is the responsibility of the research team. The research team then proposes a single collective map (also known as "aggregated map") to be discussed with the panel members in a group workshop.

During the group meeting, the aggregated map should be presented to the panel members for discussion because it should serve as a negotiation tool to reach a compromise solution. The constructivist approach is omnipresent during the process, and interactivity among actors allows the panel members to achieve convergence of opinions. As highlighted by Ackermann and Eden (2001), Cossette and Audet (2003), when this convergence of opinions is achieved in terms of form and content, the collective map is designated as "congregated" or "strategic" map. Figure 2 presents part of the congregated map developed in this study. 


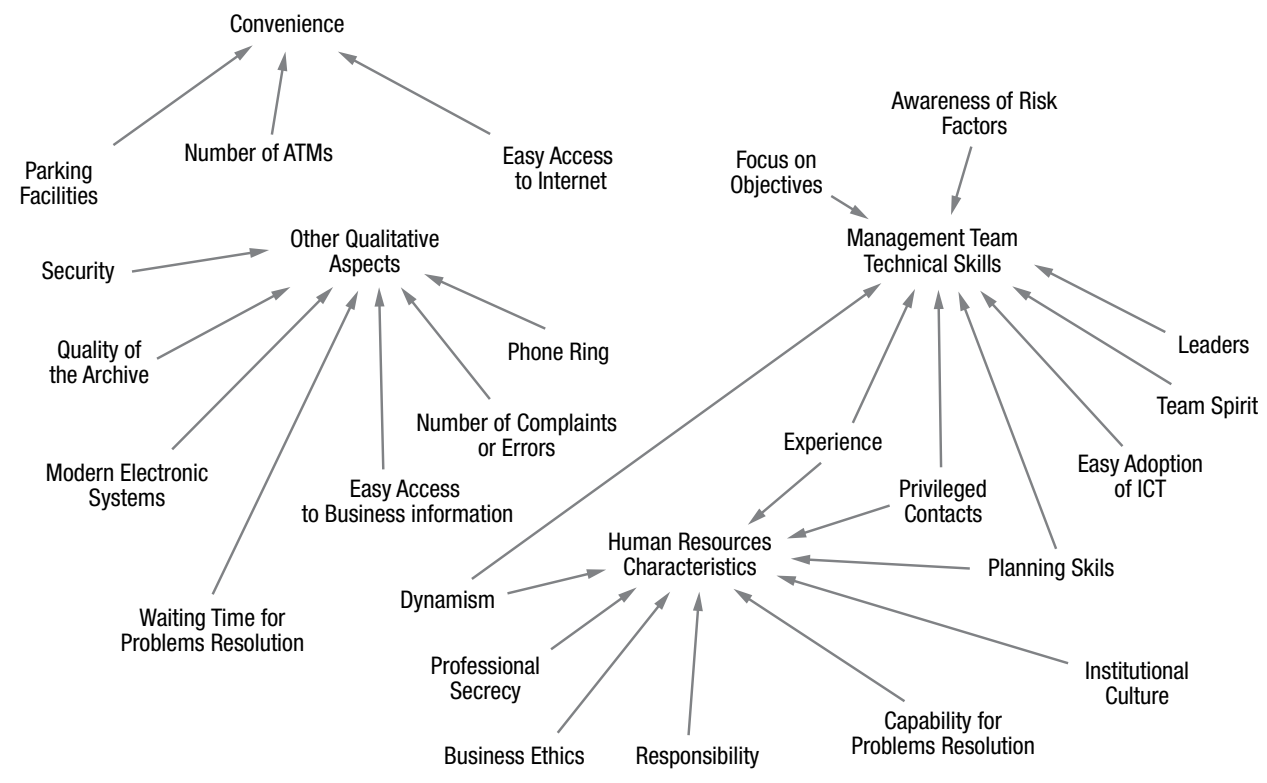

Fig. 2. Part of the strategic map

Accompanying this procedural step, one should bear in mind that the final form and/or content of a congregated map depends, among other things, on the facilitators' skills, actors involved, duration of the group meetings and circumstances undertaken. However, in our essay, the use of cognitive mapping has proved very valuable to structure and improve the understanding regarding bank branch service quality and convenience.

\subsubsection{Criteria, descriptors and impact levels}

Keeney's (1992) methodological guidelines allowed us to pass from the congregated map to the tree of performance measures. Figure 3 illustrates the final version of our service quality and convenience performance measures tree, which results from the agreement reached by the decision makers after testing for the respective properties (for further details, see Bana e Costa et al. 2008).

Based on the cognitive branches identified in the congregated map and, sequentially, on the tree structure presented in Figure 3, the decision makers defined four major evalua-

Bank Branch Selection

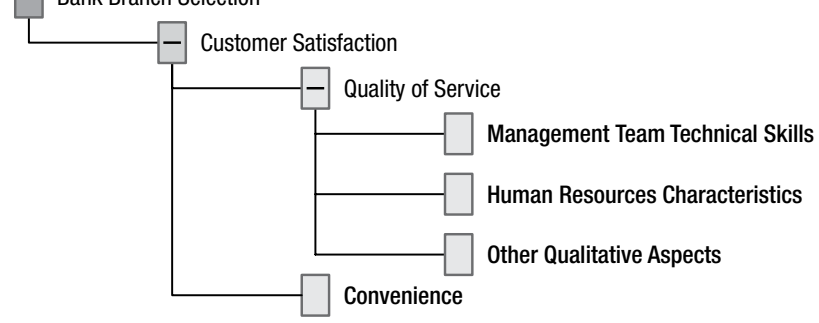

Fig. 3. Service quality and convenience performance measures tree 
tion criteria (identified as $\mathrm{CRT}_{n}$, with $n=\{1,2,3,4\}$ ). The construction of descriptors and impact levels for each one of the four criteria was the next technical procedure, and resulted from the direct interaction with the panel members. As an illustrative example, $\mathrm{CRT}_{2}$ (Human Resources Characteristics) is conceived to evaluate a bank branch's service quality strictly based on the characteristics of its internal collaborators. Those characteristics are assessed (and considered good or bad) based on a coefficient (i.e. descriptor) that balances the number of complains or errors and the number of daily operations per collaborator (i.e. the lower the ratio the better the bank branch will be). To make the $\mathrm{CRT}_{2}$ 's descriptor operational, eight ordered reference levels $\left(L_{i}\right.$ with $i=1,2, \ldots, 8$ ) (including a good level and a neutral level), were defined. As illustrated in Table 2, this procedure allows for a better evaluation of the human resources characteristics of a certain bank branch.

Table 2. Impact levels of the descriptor of the $\mathrm{CRT}_{2}$ (human resources characteristics)

\begin{tabular}{|c|c|c|}
\hline Impact level & $\begin{array}{c}\text { Reference } \\
\text { level }\end{array}$ & Description \\
\hline $\mathrm{L}_{1}$ & & Total absence of complains or errors. \\
\hline $\mathrm{L}_{2}$ & Good & N. ${ }^{\circ}$ compl. or errors / [N. ${ }^{\circ}$ daily oper. / colaborator $\left.\left.] \in\right] 0-1 \%\right]$. \\
\hline $\mathrm{L}_{3}$ & & N. ${ }^{\circ}$ compl. or errors / [N. ${ }^{\circ}$ daily oper. / colaborator] $\left.\left.\in\right] 1-1.5 \%\right]$. \\
\hline $\mathrm{L}_{4}$ & & N. ${ }^{\circ}$ compl. or errors / [N. ${ }^{o}$ daily oper. / colaborator $\left.\left.] \in\right] 1.5-2 \%\right]$. \\
\hline $\mathrm{L}_{5}$ & Neutral & N. ${ }^{\circ}$ compl. or errors / [N. ${ }^{\circ}$ daily oper. / colaborator] $\left.\left.\in\right] 2-2.5 \%\right]$. \\
\hline $\mathrm{L}_{6}$ & & N. ${ }^{\circ}$ compl. or errors / [N. ${ }^{o}$ daily oper. / colaborator $\left.\left.] \in\right] 2.5-3 \%\right]$. \\
\hline $\mathrm{L}_{7}$ & & N. ${ }^{\circ}$ compl. or errors / [N. ${ }^{\circ}$ daily oper. / colaborator $\left.\left.] \in\right] 3-3.5 \%\right]$. \\
\hline $\mathrm{L}_{8}$ & & N. ${ }^{\circ}$ compl. or errors / [N. ${ }^{\circ}$ daily oper. / colaborator] $>3.5 \%$. \\
\hline
\end{tabular}

Following Table 2, one should bear in mind that the technical procedure adopted to turn the $\mathrm{CRT}_{2}$ 's descriptor operational allowed ordering the impact levels to obtain a value function. As is recognized by the MCDA literature (Ferreira et al. 2011a), the evaluation phase may be started as soon as impact levels for all descriptors have been defined.

\subsection{The evaluation phase}

Weighting criteria is a pre-requisite for our performance evaluation framework. In this way, a group meeting was organized to obtain the experts' value judgements and consequent trade-offs among criteria (section 2.2.1). The work group session was also considered as critical in our decision process because a sample of four bank branches was evaluated and the results were discussed with and among the panel members.

\subsubsection{Value judgements and local preferences}

As stated in Bana e Costa and Vansnick (1994), MACBETH's initial framework is based on numerical representations of semi-orders for multiple thresholds. Based on a certain point of view $P V_{j}$ and supported on the mathematical principles of Doignon (1984), the authors defend that in a structure of $m$ binary relations $\left[P^{(1)}, \ldots, P^{(k)}, \ldots, P^{(m)}\right]$ (where $P^{(k)}$ 


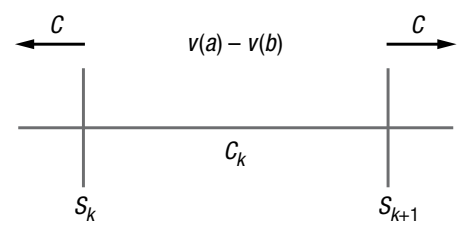

Fig. 4. Allocation of $v(a)-v(b)$ to a Category $C_{k}$

stands for a preference that is stronger the greater the $k$ ), the numerical codification of preferences is possible. As such, the MACBETH procedure consists in the association of each action of $X$ (with $X=\{a, b$, $\ldots, n\}$ being a finite set of $n$ actions), to a value $x$ (resulting from a value function $v():. \mathrm{X} \rightarrow \mathrm{R}$ ) such that differences as $v(a)-v(b)$ (with $a$ strictly more attractive than $b$ (i.e. $a P b)$ ), are as compatible as possible with the decision makers' value judgements. This means that for all pairs of actions $(a, b)$ allocated to a certain category of difference of attractiveness $C$, the differences $v(a)-v(b)$ will belong, without overlaps, to the same interval (Bana e Costa, Vansnick 1994). Accordingly, whereas two contiguous ranges correspond to two consecutive categories, the procedure consists in associating asymmetric partitions of the ray of positive reals to partition classes of ordered pairs $(a, b)$ (with $a$ $P b)$ (see Fig. 4).

Following Figure 4, and in order to define the intervals between categories of consecutive differences of attractiveness, the next technical step consists in calculating the limits $s_{k}$, which can be understood as transition thresholds. Recalling the problem of numerical representations of semi-orders for multiple thresholds, semi-multiple orders can be easily introduced as long as we wish to represent value preferences by a value function $v$ and function thresholds $s_{k}$, such as:

$$
a P^{(k)} b: s_{k}<v(a)-v(b)<s_{k+1} .
$$

Being the thresholds $s_{k}$ positive real constants, the definition of intervals between semantic differences of attractiveness becomes easier. Theoretically, being $a P^{(m)} b$, it is always possible to add a level of preference by introducing a real or fictitious action $c$, such that $c$ is more attractive than $b$, more than $a$ is more attractive than $b$. However, as discussed by Bana e Costa and Vansnick (1994), a range of differences of attractiveness has to be limited on its left by "its" zero. As such, between the origin (i.e. $s_{1}=0$ ) and $s_{m}$, an infinite number of categories and thresholds can be defined, but the last semantic category $C_{m}$ cannot be limited on its right. An illustrative example of a range of categories of difference of attractiveness is presented in Figure 5.

Recalling Bana e Costa et al. (2005), "the basic idea underlying the initial development of MACBETH was that limits of these intervals should not be arbitrarily fixed a priori, but determined simultaneously with numerical value scores for the elements of $X$ '. Following this remark, and based on the decision-maker/s' value judgements, the MACBETH technique consists in allocating the difference of attractiveness between

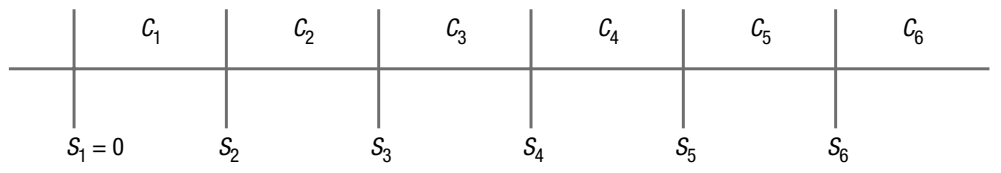

Fig. 5. Scale of categories of difference of attractiveness 
each pair of actions $(a, b) \in X$ to one of the following categories: $C_{0}=$ Null; $C_{1}=$ Very weak; $C_{2}=$ Weak; $C_{3}=$ Moderate; $C_{4}=$ Strong; $C_{5}=$ Very strong; and $C_{6}=$ Extreme (Bana e Costa et al. 2005). Illustratively, if a decision maker considers $a$ more attractive than $b$ and the difference between both actions is weak, then $(a, b) \in C_{2}$.

Following Bana e Costa et al. (1999) guidelines, we applied the MACBETH technique to our framework, considering the previously mentioned categories. For consistency purposes (Junior 2008), formulations (2) and (3) given below were also analyzed based on the experts' value judgements, i.e.,

$$
\begin{gathered}
\forall a, b \in X: v(a)>v(b) \Leftrightarrow a P b, \\
\forall k, k^{*} \in\{1,2,3,4,5,6\}, \forall a, b, c, d \in X \text { with }(a, b) \in C_{k} \\
\text { and }(c, d) \in C_{k^{*}}: k \geq k^{*}+1 \Rightarrow v(a)-v(b) \geq v(c)-v(d) .
\end{gathered}
$$

Specifically, formulation (2) presents the rational assumption that if action $a$ is strictly more attractive than action $b$ (i.e. $a P b$ ), then the value of action $a$ should be greater than the value of action $b$. This means that it is possible to associate numbers to these actions such that $v(a)>v(b)$. On the other hand, if no value difference between actions is felt and, thus, both actions are equally attractive or indifferent (i.e. $a I b$ ), then $v(a)=v(b)$, and the pair $(a, b)$ will be allocated to $C_{0}$. In this sense, and based on the different semantic categories $C_{k}$ presented before, formulation (3) states "that all of the differences allocated to one semantic preference difference category are strictly larger than those allocated to a lower category" (Bana e Costa et al. 2008). Once analyzed the consistency of the decision makers' value judgements, linear programming is then applied according to (4) (Junior 2008), and an initial scale is generated and presented for discussion.

$\operatorname{Min} v(n)$

$$
\begin{aligned}
& \text { S.T.: } \forall a, b \in X: a P b \Rightarrow v(a) \geq v(b)+1 \text {, } \\
& \forall a, b \in X: a l b \Rightarrow v(a)=v(b), \\
& \forall(a, b),(c, d) \in X \text {, if the difference of attractiveness between } \\
& a \text { and } b \text { is bigger than between } c \text { and } d \text {, then: } \\
& v(a)-v(b) \geq v(c)-v(d)+1+\delta(a, b, c, d),
\end{aligned}
$$

$v\left(a^{-}\right)=0$,

where:

$n$ is an element of $X$ so that $\forall a, b, c, \ldots \in X: n(P \cup I) a, b, c, \ldots$,

$a^{-}$is an element of $X$ so that $\forall a, b, c, \ldots \in X: a, b, c, \ldots(P \cup I) a^{-}$,

$\delta(a, b, c, d)$ is the minimal number of categories of difference of attractiveness

between the difference of attractiveness between $a$ and $b$ and the

difference of attractiveness between $c$ and $d$.

According to formulation (4), $n$ represents the most attractive (or at least as attractive as the others) element of $X$ (i.e. $n(P \cup I) a, b, c, \ldots)$, and its value minimization guarantees 
the minimal length of the initial scale. Accordingly, $a^{-}$represents the less attractive (or at least as attractive as the others) element of $X$ (i.e. $\left.a, b, c, \ldots(P \cup I) a^{-}\right)$, and its value is anchored to the scale's "zero" (for further technical explanations, see Bana e Costa et al. 2008).

Methodologically, MACBETH is based on a direct question-answer procedure, where panel members pairwise compare alternatives and give a qualitative judgement on their difference of attractiveness. In assisting the process, value judgement matrices are repeatedly executed, and the filling process continues until a local preference scale is defined for each descriptor included in the model. The matrix and value function obtained for $\mathrm{CRT}_{4}$ are presented in Figure 6, which allowed for further discussion with and among decision makers.

It seems important to underline, however, that the M-MACBETH software was extremely helpful in dealing with inconsistencies resulting from the decision maker's value judgements, which were promptly overcome by further discussion and/or judgements reconsideration. According to Bana e Costa and Chagas (2004) and Bana e Costa et al. (2005), mutual preferential independence tests were also conducted to guarantee preferential independence among evaluation criteria.

The definition of cardinal value scales for all descriptors is an important technical step that allows partial assessment of bank branches. However, to get an overall evaluation, trade-offs (also known as substitution rates, weights or compensations among criteria) need to be calculated.

\begin{tabular}{|c|c|c|c|c|c|c|c|c|c|}
\hline \multicolumn{9}{|c|}{ 邻, Human Resources Characteristics } & $\sqrt{x}$ \\
\hline 司 & L1 & L2 & L3 & L4 & L5 & L6 & L7 & L8 & $\begin{array}{l}\text { Current } \\
\text { scale }\end{array}$ \\
\hline $\mathrm{L} 1$ & no & weak & moderate & strong & strong & strong & v. strong & v. strong & 133.33 \\
\hline L2 & & no & weak & moderate & strong & strong & strong & v. strong & 100.00 \\
\hline L3 & & & no & weak & moderate & strong & strong & strong & 66.67 \\
\hline L4 & & & & no & weak & moderate & strong & strong & 33.33 \\
\hline L5 & & & & & no & weak & moderate & strong & 0.00 \\
\hline L6 & & & & & & no & weak & moderate & -33.33 \\
\hline L7 & & & & & & & no & weak & -66.67 \\
\hline L8 & & & & & & & & no & -100.00 \\
\hline \multicolumn{10}{|c|}{ Consistent judgements } \\
\hline 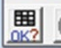 & & & 畔背: & & 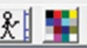 & & & & \\
\hline
\end{tabular}

\begin{tabular}{|c|c|c|c|}
\hline พู้ & Human Res & ources Char & acteristics \\
\hline & $\begin{array}{c}\text { Current } \\
\text { scale }\end{array}$ & $\begin{array}{c}\text { MACBETH } \\
\text { anchored }\end{array}$ & $\begin{array}{c}\text { MACBETH } \\
\text { basic }\end{array}$ \\
\hline L1 & 133.33 & 133.33 & 14.00 \\
\hline $\mathrm{L} 2$ & 100.00 & 100.00 & 12.00 \\
\hline L3 & 66.67 & 66.67 & 10.00 \\
\hline L4 & 33.33 & 33.33 & 8.00 \\
\hline L5 & 0.00 & 0.00 & 6.00 \\
\hline L6 & -33.33 & -33.33 & 4.00 \\
\hline $\mathrm{L7}$ & -66.67 & -66.67 & 2.00 \\
\hline L8 & -100.00 & -100.00 & 0.00 \\
\hline
\end{tabular}

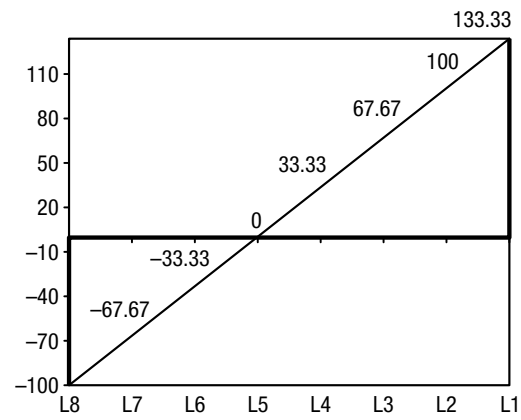

Fig. 6. Value judgements, proposed scales and value function for $\mathrm{CRT}_{4}$ 


\subsubsection{The trade-offs procedures}

To obtain the compensation rates among criteria, decision makers were asked to rank the four criteria in terms of overall attractiveness. To support the ranking procedure, an alternative $a_{0}$ (composed of the worst impact levels) was compared to an alternative $a_{n}$ (composed of the best impact levels), and the different preferences of the decision makers were registered in a matrix of comparisons (for further details on this technical procedure, see Bana e Costa, Chagas 2004). Once ordered the criteria, with $\mathrm{CRT}_{2}$ being considered overall preferable to the others, the panel members were invited to express their value judgements in terms of difference of attractiveness among criteria. Based on the same procedure previously followed for the local scales (cf. Fig. 6), an initial scale and respective trade-offs were made explicit and proposed for discussion (Fig. 7). As can be seen in Figure 7, the M-MACBETH software made the trade-offs calculi easier and enabled the construction of an additive value model as presented in (5) (Bana e Costa et al. 2008):

$V(a)=\sum_{i=1}^{n} x_{i} v_{i}(a)$ with $\sum_{i=1}^{n} x_{i}=1$ and $x_{i}>0, v_{i}\left(\operatorname{good}_{i}\right)=100$ and $v_{i}\left(\right.$ neutral $\left._{i}\right)=0$.

Following formulation (5), it should be clarified that this additive model allows for the aggregation of the partial scores $v_{i}(a)$ and consequent calculation of the overall score $V(a)$. Moreover, $v_{i}\left(\operatorname{good}_{i}\right)$ and $v_{i}\left(\right.$ neutral $\left._{i}\right)$ represent the partial scores of two specific performance levels (i.e. good and neutral), that have been defined in all descriptors to facilitate cognitive comparisons. In this sense, based on the discussion with the decision makers, it became possible to approve the trade-offs and assess bank branches' partial and overall service quality and convenience.

\begin{tabular}{|c|c|c|c|c|c|c|}
\hline \multicolumn{6}{|c|}{ Wheighting (Bank Branch Selection) } & $x$ \\
\hline 國 & [CRT2] & [CRT1] & [CRT4] & [CRT3] & [all lower] & $\begin{array}{l}\text { Current } \\
\text { scale }\end{array}$ \\
\hline [CRT2] & no & weak & moderate & strong & positive & 42.85 \\
\hline [CRT1] & & no & moderate & strong & positive & 33.33 \\
\hline [CRT4] & & & no & moderate & positive & 19.05 \\
\hline [CRT3] & & & & no & positive & 4.77 \\
\hline [all lower] & & & & & no & 0.00 \\
\hline \multicolumn{7}{|c|}{ Consistent judgements } \\
\hline 贯 & (2)1 & & $\ln$ 烈 & 界F & 悬 & \\
\hline
\end{tabular}

\begin{tabular}{l}
\hline \begin{tabular}{|l|r|r|r|}
\hline Th. Weighting (Bank Branch Selection) \\
\hline & $\begin{array}{c}\text { Current } \\
\text { scale }\end{array}$ & $\begin{array}{c}\text { MACBETH } \\
\text { anchored }\end{array}$ & $\begin{array}{c}\text { MACBETH } \\
\text { basic }\end{array}$ \\
\hline [CRT2] & 42.85 & 42.85 & 9.00 \\
\hline [CRT1] & 33.33 & 33.33 & 7.00 \\
\hline [CRT4] & 19.05 & 19.05 & 4.00 \\
\hline [CRT3] & 4.77 & 4.77 & 1.00 \\
\hline [all lower] & 0.00 & 0.00 & 0.00 \\
\hline
\end{tabular}
\end{tabular}

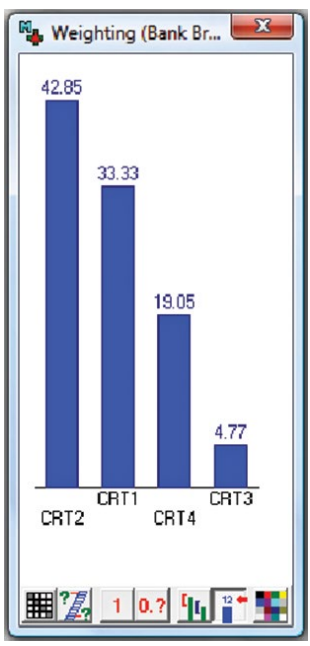

Fig. 7. Value judgements, proposed scales and criteria weights 


\subsubsection{Measuring bank branch service quality and convenience}

For testing our service quality and convenience evaluation framework, data on bank branch performance were formally requested from the Portuguese public bank Caixa Geral de Depósitos (CGD), which is, perhaps, the largest bank operating in Portugal. It seems relevant to point out that the information on four bank branches (called Alphas from now on) was randomly and anonymously provided by the bank's administration, and resulted from internal surveys referred to a single period of time (month). Despite these limitations, the information provided was extremely useful, not only to test our service quality and convenience evaluation system but also to augment the interest and discussion among the decision makers involved in the process.

Considering the descriptors and the value functions previously obtained for each criterion, the first measurement step was to calculate partial performance values for each one of the alphas (Fig. 8 and Table 3).

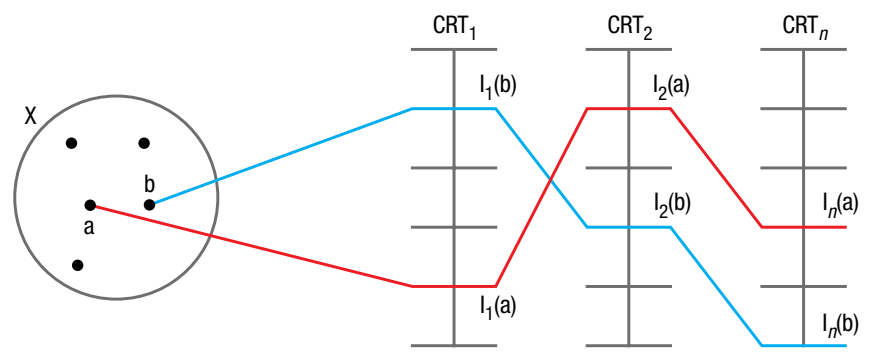

Fig. 8. Partial performance conceptual scheme

Table 3. Levels and partial values revealed by the alphas

\begin{tabular}{lcccccccc}
\hline & \multicolumn{2}{c}{$\mathrm{CRT}_{1}$} & \multicolumn{2}{c}{$\mathrm{CRT}_{2}$} & \multicolumn{2}{c}{$\mathrm{CRT}_{3}$} & \multicolumn{2}{c}{$\mathrm{CRT}_{4}$} \\
\hline Alpha 1 & $\mathrm{~L}_{2}$ & 300 & $\mathrm{~L}_{3}$ & 66.67 & $\mathrm{~L}_{6}$ & -800 & $\mathrm{~L}_{2}$ & 100 \\
\hline Alpha 2 & $\mathrm{~L}_{2}$ & 300 & $\mathrm{~L}_{4}$ & 33.33 & $\mathrm{~L}_{6}$ & -800 & $\mathrm{~L}_{5}$ & 25 \\
\hline Alpha 3 & $\mathrm{~L}_{2}$ & 300 & $\mathrm{~L}_{4}$ & 33.33 & $\mathrm{~L}_{6}$ & -800 & $\mathrm{~L}_{6}$ & 0 \\
\hline Alpha 4 & $\mathrm{~L}_{5}$ & 0 & $\mathrm{~L}_{2}$ & 100 & $\mathrm{~L}_{6}$ & -800 & $\mathrm{~L}_{6}$ & 0 \\
\hline Good & $\mathrm{L}_{4}$ & 100 & $\mathrm{~L}_{2}$ & 100 & $\mathrm{~L}_{2}$ & 100 & $\mathrm{~L}_{2}$ & 100 \\
\hline Neutral & $\mathrm{L}_{5}$ & 0 & $\mathrm{~L}_{5}$ & 0 & $\mathrm{~L}_{3}$ & 0 & $\mathrm{~L}_{6}$ & 0 \\
\hline
\end{tabular}

To facilitate the analysis of Table 3, it is appropriated to point out that Good and Neutral are two fictitious bank branches introduced in the model to simplify cognitive comparisons. Good stands for a bank branch that performs at a good level for all the criteria considered, and Neutral represents a bank branch that performs at neutral levels (i.e. neither attractive nor unattractive) for those same evaluation criteria. By following this procedure, performance comparisons among branches became possible (e.g. Alpha 4 is 
the worst performer on $\mathrm{CRT}_{1}$, which corresponds to the neutral level, but it is also the best performer on $\mathrm{CRT}_{2}$ ). These comparisons among performances are useful not only because they enable the panel members to better understand the evaluation process but also because they allow proposing and/or implementing well localized improvement suggestions. The partial and overall performance values of the six bank branches evaluated (Good and Neutral included) are presented in Table 4.

Table 4. Partial values and overall attractiveness revealed by the alphas

\begin{tabular}{|c|c|c|c|c|c|}
\hline \multicolumn{5}{|c|}{ Wy Table of scores } & \multirow{2}{*}{$\begin{array}{r}x \\
\text { CRT4 }\end{array}$} \\
\hline Options & Overall & CRT1 & CRT2 & CRT3 & \\
\hline Alpha 1 & 109.45 & 300.00 & 66.67 & -800.00 & 100.00 \\
\hline Alpha 2 & 80.87 & 300.00 & 33.33 & -800.00 & 25.00 \\
\hline Alpha 3 & 76.11 & 300.00 & 33.33 & -800.00 & 0.00 \\
\hline Alpha 4 & 4.69 & 0.00 & 100.00 & -800.00 & 0.00 \\
\hline Good & 100.00 & 100.00 & 100.00 & 100.00 & 100.00 \\
\hline Neutral & 0.00 & 0.00 & 0.00 & 0.00 & 0.00 \\
\hline \multicolumn{2}{|c|}{ Weights: } & 0.3333 & 0.4285 & 0.0477 & 0.1905 \\
\hline
\end{tabular}

Basing our discussion on Table 4, Alpha 1 appears to be the best bank branch with an overall score of 109.45, while Alpha 4 may be considered the worst performer with an overall score of 4.69. Nonetheless, these results should be faced with proper reservation. As stated by Nowak (2011), the emphasis should be placed on the constructive analysis and discussion that emerged from the panel members.

\subsubsection{Analysing results}

The bank branch service quality and convenience evaluation system developed above allowed the panel members to: (1) discriminate the alphas according to their own value judgements; (2) compare the alphas with the Good and Neutral references; (3) promote discussion and increase transparency in the decision framework; (4) serve as a learning mechanism for improvement suggestions; and (5) show how cognitive maps and MCDA can be integrated in a bank branch service quality evaluation context.

Once a final ranking is approved by the decision makers, the evaluation phase is considered complete (Bana e Costa, Chagas 2004); however, additional analyses such as sensitivity and robustness analyses are encouraged to validate results and analyze their stability, which should serve as basis for further discussion. Figure 9 shows the sensitivity analysis carried out for $\mathrm{CRT}_{2}$.

Based on Figure 9 and recalling previous discussion, the weight attributed to $\mathrm{CRT}_{2}$ is 42.85. However, the sensitivity analysis carried out for this criterion allows us to conclude that the model is strong because the criterion's weight can vary significantly without violating the alphas' ranking position and, consequently, the value judgements of the decision makers. However, because sensitivity analysis deals with variations of isolated variables, other types of analyses were carried out. Figure 10 illustrates the robustness analysis developed, which considers possible variations of different variables at the same time. 


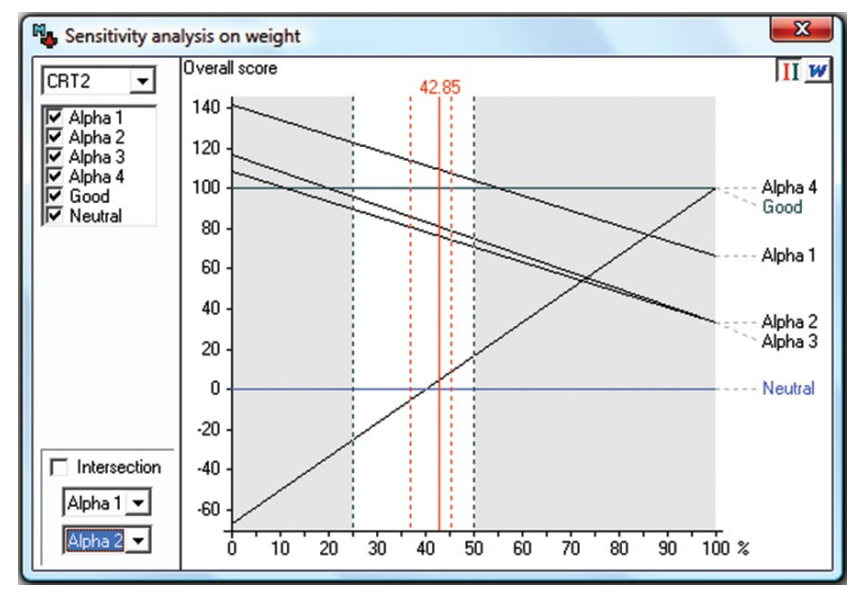

Fig. 9. Sensitivity analysis on $\mathrm{CRT}_{2}$ 's weight
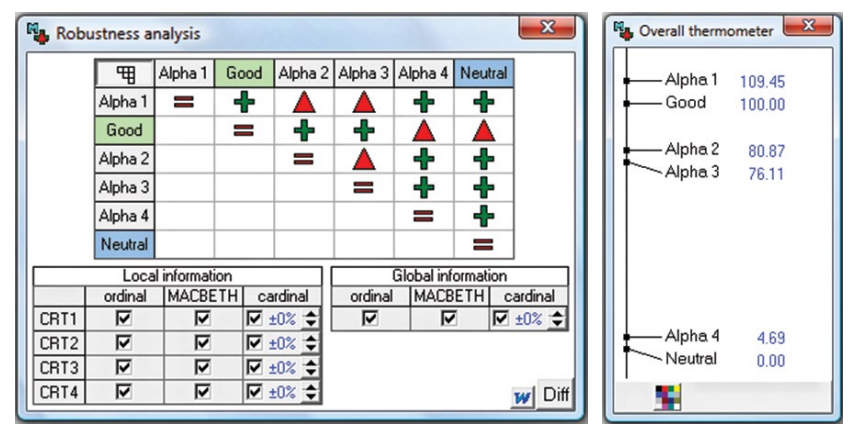

Fig. 10. Robustness analysis and overall thermometer

Both sensitive and robustness analyses were supported by the M-MACBETH software. However, in the particular case of the robustness analysis, one should clarify that each cross represents a typical situation of additive dominance, which means that despite of a better overall performance, a certain alpha does not present the best local performance in all the criteria (e.g. Alpha 2 (with an overall score of 80.87) is overall more attractive than Alpha 4 (with an overall score of 4.69), but Alpha 2 performs worse than Alpha 4 on $\mathrm{CTR}_{2}$ (cf. Table 4)). On the other hand, each triangle represents a situation of classic dominance (i.e. no matter which trade-offs are obtained, a certain alpha dominates the others in terms of partial and overall performance e.g. Alpha 1 is always better than or at least equal to Alpha 2).

Our previous analysis indicates that the evaluation framework developed is strong and robust, and presents encouraging results. Nonetheless, these results should be treated with appropriate reservation. Some of the reasons why our results should be treated with reservation are discussed in the recommendations phase of the study. 


\subsection{The recommendations phase of the study}

Our bank branch service quality and convenience evaluation framework is encouraging based on the satisfaction expressed by the decision makers. Nevertheless, it should be emphasized that our evaluation procedure is process-oriented, where a non-prescriptive position has always been assumed. From this perspective, our performance evaluation system should be primarily seen as a learning mechanism and not as a final solution and/or tool to reach optimal solutions. Since the results depend on the context and actors involved, any generalization should be questioned before implementation. This may be considered a shortcoming. However, the integrated use of cognitive maps and MCDA techniques also offers adjustment possibilities and this, on its turn, increases the potentialities of the framework.

\section{Discussions and conclusions}

Service quality and convenience at the retail bank branch level are inherently difficult to measure; however, we have presented an MCDA framework that attempts to evaluate bank branches. Considering the recent progress that has taken place, it seems generally agreed that several aspects still require discussion and clarification. With that purpose in mind, we extend the research in Ferreira et al. (2011a) and report a few outcomes of the interaction maintained with directors from the five largest banks in Portugal. While bank customers' were not directly involved in the design of the performance measurement framework, the evaluation criteria identified by the directors, and which are represented in the performance measures tree (see Fig. 3), capture some of the factors that most impact customers' perceptions regarding the quality of service and convenience of bank branches (e.g. number of complains, errors, easy access to information and services, waiting times and security) (see the strategic map diagrammed in Fig. 2).

In practical terms, our framework allowed us to deal with two major limitations of existing methodologies for performance measurement: (1) the way performance measures are often selected may lead to the omission of relevant evaluation criteria; and (2) there seems to be lack of transparency in the way compensations among those same criteria are obtained. Using cognitive maps integrated with the MACBETH approach we were able to support criteria selection and obtain compensation rates. To the best of our knowledge, we are unaware of any prior evidence reporting the integrated use of these two methodologies to support the conception of bank branch service quality and convenience evaluation systems.

Among other things, our performance evaluation system may be particularly useful to: (1) monitor the progress of the branches over time; (2) identify and desirably implement corrective actions; (3) increase transparency in criteria selection and trade-offs calculation; and (4) incorporate professional know-how and experience in the decision making process, in order to increase the realism of the evaluation process.

It should be noted, however, that the procedure proposed in this study is not without its own limitations and weaknesses. For example, as previously stated, our results depend on the context and decision makers involved. Nonetheless, earlier research carried out by Weber and Borcherding (1993) suggests that no superior methodological approach 
exists and that the choice of method is strongly dependent on the decision context, making it very difficult to prove that one approach or method is superior to others in supporting the decision making process (for a broader discussion, see also Ananda, Herath 2009). In this sense, our results should be analyzed with reservations, and further research (including case studies) is necessarily encouraged. We then recommend conducting: (1) a different panel study and within a different country; (2) a survey to receive feedback from more than just a few experts; and (3) a comparative study to confront the results obtained from different methodological applications in this particular context. We are optimistic that possible improvements will help strengthen the potential and interest of the proposal presented herein.

\section{References}

Acar, A.; Zehir, C. 2010. The harmonized effects of generic strategies and business capabilities on business performance, Journal of Business Economics and Management 11(4): 689-711. http://dx.doi.org/10.3846/jbem.2010.34

Ackermann, F. 2012. Problem structuring methods 'in the dock': arguing the case for soft OR, European Journal of Operational Research 219(3): 652-658.

http://dx.doi.org/10.1016/j.ejor.2011.11.014

Ackermann, F.; Eden, C. 2001. SODA - Journey making and mapping in practice, in J. Rosenhead, J. Mingers (Eds.). Rational analysis for a problematic world revisited: problem structuring methods for complexity, uncertainty and conflict. $2^{\text {nd }}$ ed. Chichester: John Wiley \& Sons, 43-60.

Ackermann, F.; Eden, C. 2011. Strategic management of stakeholders: theory and practice, Long Range Planning 44(3): 179-196. http://dx.doi.org/10.1016/j.lrp.2010.08.001

Ananda, J.; Herath, G. 2009. A critical review of multi-criteria decision making methods with special reference to forest management and planning, Ecological Economics 68(10): 2535-2548. http://dx.doi.org/10.1016/j.ecolecon.2009.05.010

Arbore, A.; Busacca, B. 2009. Customer satisfaction and dissatisfaction in retail banking: exploring the asymmetric impact of attribute performances, Journal of Retailing and Consumer Services 16(4): 271-280. http://dx.doi.org/10.1016/j.jretconser.2009.02.002

Athanassopoulos, A. 1997. Service quality and operating efficiency synergies for management control in the provision of financial services: evidence from Greek bank branches, European Journal of Operational Research 98(2): 300-313. http://dx.doi.org/10.1016/S0377-2217(96)00349-9

Bana e Costa, C.; Chagas, M. 2004. A career choice problem: an example of how to use MAC$\mathrm{BETH}$ to build a quantitative value model based on qualitative value judgements, European Journal of Operational Research 153(2): 323-331. http://dx.doi.org/10.1016/S0377-2217(03)00155-3

Bana e Costa, C.; De Corte, J.; Vansnick, J. 2005. On the mathematical foundations of MAC$\mathrm{BETH}$, in J. Figueira, S. Greco, M. Ehrgott (Eds.). Multiple criteria decision analysis: the state of the art surveys. New York: Springer, 409-442.

Bana e Costa, C.; Ensslin, L.; Corrêa, E.; Vansnick, J. 1999. Decision support systems in action: integrated application in a multicriteria decision aid process, European Journal of Operational Research 113(2): 315-335. http://dx.doi.org/10.1016/S0377-2217(98)00219-7

Bana e Costa, C.; Lourenço, J.; Chagas, M.; Bana e Costa, J. 2008. Development of reusable bid evaluation models for the Portuguese electric transmission company, Decision Analysis 5(1): 22-42. http://dx.doi.org/10.1287/deca.1080.0104

Bana e Costa, C.; Vansnick, J. 1994. MACBETH: an interactive path towards the construction of cardinal value functions, International Transactions in Operational Research 1(4): 489-500. http://dx.doi.org/10.1016/0969-6016(94)90010-8 
Belton, V.; Stewart, T. 2002. Multiple criteria decision analysis: an integrated approach. Dordrecht: Kluwer Academic Publishers.

Brignall, S. 1992. Performance measurement systems as change agents: a case for further research, Research Paper 72. Warwick: Warwick Business School.

Camanho, A.; Dyson, R. 2005. Cost efficiency measurement with price uncertainty: a DEA application to bank branches assessments, European Journal of Operational Research 161(2): 432-446. http://dx.doi.org/10.1016/j.ejor.2003.07.018

Charnes, A.; Cooper, W.; Rhodes, E. 1978. Measuring the efficiency of decision making units, European Journal of Operational Research 2(6): 429-444.

http://dx.doi.org/10.1016/0377-2217(78)90138-8

Cossette, P.; Audet, M. 2003. Qu'est qu'une carte cognitive?, in P. Cossette (Ed.). Cartes Cognitives et Organizations, Les Éditions de L'ADREG, 31-60 [online], [cited February 2012]. Available from Internet: http://asso.nordnet.fr/adreg/Adreg_05.pdf

Davis, S.; Albright, T. 2004. An investigation of the effect of the Balanced Scorecard implementation on financial performance, Management Accounting Research 15(2): 135-153.

http://dx.doi.org/10.1016/j.mar.2003.11.001

Dekker, D.; Post, T. 2001. A quasi-concave DEA model with an application for bank branch performance evaluation, European Journal of Operational Research 132(2): 296-311.

http://dx.doi.org/10.1016/S0377-2217(00)00153-3

Doignon, J. 1984. Threshold representations of multiple semiorders, SIAM Journal of Algebraic Discrete Methods 8(1): 77-84. http://dx.doi.org/10.1137/0608005

Eden, C. 2004. Analyzing cognitive maps to help structure issues or problems, European Journal of Operational Research 159(3): 673-686. http://dx.doi.org/10.1016/S0377-2217(03)00431-4

Eden, C.; Ackermann, F. 2001a. Group decision and negotiation in strategy making, Group Decision and Negotiation 10(4): 119-140. http://dx.doi.org/10.1023/A:1008710816126

Eden, C.; Ackermann, F. 2001b. SODA - the principles, in J. Rosenhead, J. Mingers (Eds.). Rational analysis for a problematic world revisited: problem structuring methods for complexity, uncertainty and conflict. $1^{\text {st }}$ ed. Chichester: John Wiley \& Sons, 21-41.

Eden, C.; Banville, C. 2003. Construction d'une vision stratégique au moyen de la cartographie cognitive assisté par ordinateur, in P. Cossette (Ed.). Cartes Cognitives et Organisations, Les Éditions de L'ADREG, 125-166 [online], [cited February 2012]. Available from Internet: http:// asso.nordnet.fr/adreg/Adreg_05.pdf.

Ferreira, F.; Santos, S.; Rodrigues, P. 2011a. Adding value to bank branch performance evaluation using cognitive maps and MCDA: a case study, Journal of the Operational Research Society 62(7): 1320-1333. http://dx.doi.org/10.1057/jors.2010.111

Ferreira, F.; Spahr, R.; Pereira, J. 2011b. New banking trends, MCDA and financial decisions: insights and a framework for retail banking, Banks and Bank Systems 6(2): 23-35.

Halkos, G.; Salamouris, D. 2004. Efficiency measurement of the Greek commercial banks with the use of financial ratios: a data envelopment analysis approach, Management Accounting Research 15(2): 201-224. http://dx.doi.org/10.1016/j.mar.2004.02.001

Howick, S.; Ackermann, F. 2011. Mixing OR methods in practice: past, present and future directions, European Journal of Operational Research 215(3): 503-511.

http://dx.doi.org/10.1016/j.ejor.2011.03.013

Jackson III, W.; Nandakumarb, P.; Roth, A. 2003. Market structure, consumer banking, and optimal level of service quality, Review of Financial Economics 12(1): 49-63.

http://dx.doi.org/10.1016/S1058-3300(03)00006-5 
Jahanshahloo, G.; Amirteimoori, A.; Kordrostami, S. 2004. Multi-component performance, progress and regress measurement and shared inputs and outputs in DEA for panel data: an application in commercial bank branches, Applied Mathematics and Computation 151(1): 1-16. http://dx.doi.org/10.1016/S0096-3003(03)00318-7

Junior, H. 2008. Multicriteria approach to data envelopment analysis, Pesquisa Operacional 28(2): 231-242. http://dx.doi.org/10.1590/S0101-74382008000200004

Kaplan, R.; Norton, D. 1992. The balanced scorecard: measures that drive performance, Harvard Business Review 70(1): 71-79.

Karatepea, O.; Yavasb, U.; Babakus, E. 2005. Measuring service quality of banks: scale development and validation, Journal of Retailing and Consumer Services 12(5): 373-383.

http://dx.doi.org/10.1016/j.jretconser.2005.01.001

Keeney, R. 1992. Value-focused thinking: a path to creative decision making. Harvard: Harvard University Press.

Korsakienè, R. 2004. Determining competitive advantage: the analytical hierarchic process, Journal of Business Economics and Management 5(4): 205-215.

http://dx.doi.org/10.1080/16111699.2004.9636084

Lau, C.; Sholihin, M. 2005. Financial and non-financial performance measures: how do they affect job satisfaction?, British Accounting Review 37(4): 389-413.

http://dx.doi.org/10.1016/j.bar.2005.06.002

Lee, P.; Cheng, T.; Yeung, A.; Lai, K. 2011. An empirical study of transformational leadership, team performance and service quality in retail banks, Omega 39(6): 690-701.

http://dx.doi.org/10.1016/j.omega.2011.02.001

Lovell, C.; Pastor, J. 1997. Target setting: an application to a bank branch network, European Journal of Operational Research 98(2): 290-299. http://dx.doi.org/10.1016/S0377-2217(96)00348-7

Manandhar, R.; Tang, J. 2002. The evaluation of bank branch performance using data envelopment analysis: a framework, Journal of High Technology Management Research 13(1): 1-17. http://dx.doi.org/10.1016/S1047-8310(01)00045-1

Mihelis, G.; Grigoroudis, E.; Siskos, Y.; Politis, Y.; Malandrakis, Y. 2001. Customer satisfaction measurement in the private bank sector, European Journal of Operational Research 130(2): 347-360. http://dx.doi.org/10.1016/S0377-2217(00)00036-9

Neely, A.; Gregory, M.; Platts, K. 1995. Performance measurement system design: a literature review and research agenda, International Journal of Operations and Production Management 15(4): 80-116. http://dx.doi.org/10.1108/01443579510083622

Nowak, M. 2011. Interactive multicriteria decision aiding under risk: methods and applications, Journal of Business Economics and Management 12(1): 69-91.

http://dx.doi.org/10.3846/16111699.2011.555366

Oliveira, P.; Hippelb, von E. 2011. Users as service innovators: the case of banking services, Research Policy 40(6): 806-818. http://dx.doi.org/10.1016/j.respol.2011.03.009

Pan, Y.; Sheng, S.; Xie, F. 2012. Antecedents of customer loyalty: an empirical synthesis and reexamination, Journal of Retailing and Consumer Services 19(9): 150-158.

http://dx.doi.org/10.1016/j.jbusres.2012.04.014

Paradi, J.; Schaffnit, C. 2004. Commercial branch performance evaluation and results communication in a Canadian bank: a DEA application, European Journal of Operational Research 156(3): 719-735. http://dx.doi.org/10.1016/S0377-2217(03)00108-5

Podvezko, V. 2009. Application of AHP technique, Journal of Business Economics and Management 10(2): 181-189. http://dx.doi.org/10.3846/1611-1699.2009.10.181-189 
Serna, R. 2005. Where are the bank branches in my community? An analysis of branch distribution in low-income neighborhoods, California Reinvestment Coalition Report [online], [cited February 2006]. Available from Internet: http://www.calreinvest.org

Suwignjo, P.; Bititci, U.; Carrie, A. 2000. Quantitative models for performance measurement system, International Journal of Production Economics 64(1/3): 231-241.

http://dx.doi.org/10.1016/S0925-5273(99)00061-4

Weber, M; Borcherding, K. 1993. Behavioral influences on weight judgments in multiattribute decision making, European Journal of Operational Research 67(1): 1-12.

http://dx.doi.org/10.1016/0377-2217(93)90318-H

Wu, D.; Yang, Z.; Liang, L. 2006. Using DEA-neural network approach to evaluate branch efficiency of a large Canadian bank, Expert Systems with Applications 31(1): 108-115.

http://dx.doi.org/10.1016/j.eswa.2005.09.034

Yang, Z. 2009. Assessing the performance of Canadian bank branches using data envelopment analysis, Journal of the Operational Research Society 60(6): 771-780.

http://dx.doi.org/10.1057/palgrave.jors.2602619

Fernando A. F. FERREIRA is an Adjunct Professor and Vice-President of the Scientific Council at the School of Management and Technology of the Polytechnic Institute of Santarém, Portugal, and Adjunct Research Professor at the University of Memphis, TN, USA. He holds a PhD in Quantitative Methods Applied to Economics and Management from the University of Algarve, Portugal, and received his MSc in Economic and Business Sciences from the University of Algarve and the Technical University of Lisbon, Portugal. In 2009, he was granted with a Calouste Gulbenkian Foundation fellowship for Post-Doctoral studies at the Fogelman College of Business and Economics of the University of Memphis. He has authored books, book chapters, peer-reviewed papers and made many conference presentations. His main research interests include multiple criteria decision analysis and integrated systems for performance measurement in the banking sector.

Sérgio P. SANTOS is an Assistant Professor at the Faculty of Economics of the University of Algarve and a member of the Centre for Advanced Studies in Management and Economics at the University of Évora, Portugal. He holds a PhD in Management Science from the University of Strathclyde, and a MA in Economics and Econometrics from the University of Manchester, UK. His main research interests include performance measurement and management in the private and public sectors. $\mathrm{He}$ has published in national and international journals such as Omega - The International Journal of Management Science, the International Journal of Production and Operations Management and the Journal of the Operational Research Society

Paulo M. M. RODRIGUES is an economist at the Economics and Research Department of the Banco de Portugal, and Professor of Econometrics at NOVA School of Business and Economics, Universidade Nova de Lisboa, Portugal. He received his $\mathrm{PhD}$ and MA from the University of Manchester, UK. Previously he was Associate Professor at the University of Algarve, Portugal, a Jean Monnet Fellow at the European University Institute in Florence, Italy, and Visiting Scholar at the University of Navarra, Spain, the Institute for Advanced Studies in Vienna, Austria, and the University of British Columbia, Vancouver, Canada.

Ronald W. SPAHR is a Professor and Former Chairman in the Department of Finance, Insurance and Real Estate of the Fogelman College of Business and Economics of the University of Memphis, TN, USA. He received his $\mathrm{PhD}$ and MBA from the University of Wisconsin-Madison, MS in Operations Management from the University of Southern California and BS in Mechanical Engineering from South Dakota State University. Previously, he was the National City Bank Distinguished Professor of Banking and Finance at the University of Illinois, Belk Distinguished Professor of Finance at the University of North Carolina and Professor of Finance at the University of Wyoming. He has also lectured at a number of European universities. 